This item was submitted to Loughborough's Research Repository by the author.

Items in Figshare are protected by copyright, with all rights reserved, unless otherwise indicated.

\title{
Effectiveness of low speed autonomous emergency braking in real-world rear-end crashes
}

PLEASE CITE THE PUBLISHED VERSION

http://dx.doi.org/10.1016/j.aap.2015.03.029

PUBLISHER

(c) Elsevier Ltd

VERSION

AM (Accepted Manuscript)

\section{PUBLISHER STATEMENT}

This work is made available according to the conditions of the Creative Commons Attribution-NonCommercialNoDerivatives 4.0 International (CC BY-NC-ND 4.0) licence. Full details of this licence are available at: https://creativecommons.org/licenses/by-nc-nd/4.0/

\section{LICENCE}

CC BY-NC-ND 4.0

\section{REPOSITORY RECORD}

Fildes, Brian, Michael Keall, Niels Bos, Anders Lie, Yves Page, Claus-Henry Pastor, Lucia Pennisi, Matteo Rizzi, Pete Thomas, and Claes Tingvall. 2015. "Effectiveness of Low Speed Autonomous Emergency Braking in Real-world Rear-end Crashes". Loughborough University. https://hdl.handle.net/2134/17331. 
Elsevier Editorial System(tm) for Accident Analysis \& Prevention

Manuscript Draft

Manuscript Number: AAP-D-14-00692R2

Title: EFFECTIVENESS OF LOW SPEED AUTONOMOUS EMERGENCY BRAKING IN REAL-WORLD REAREND CRASHES

Article Type: Full Length Paper

Keywords: AEB Technology, Effectiveness, Meta-Analysis, Real-World, Rear-End Crashes, Evaluation

Corresponding Author: Prof. Brian Fildes, PhD

Corresponding Author's Institution: Monash University Accident Research Centre

First Author: Brian Fildes, PhD

Order of Authors: Brian Fildes, PhD; Michael Keall, PhD; Niels Bos; Anders Lie, PhD; Yves Page; Claus-

Henry Pastor; Lucia Pennisi; Matteo Rizzi; Pete Thomas, PhD; Claes Tingvall, PhD

Abstract: This study set out to evaluate the effectiveness of low speed autonomous emergency braking (AEB) technology in current model passenger vehicles, based on real-world crash experience. The Validating Vehicle Safety through Meta-Analysis (VVSMA) group comprising a collaboration of government, industry consumer organisations and researchers, pooled data from a number of countries using a standard analysis format and the established MUND approach. Induced exposure methods were adopted to control for any extraneous effects. The findings showed a 38 percent overall reduction in rear-end crashes for vehicles fitted with AEB compared to a comparison sample of similar vehicles. There was no statistical evidence of any difference in effect between urban $(\leq 60 \mathrm{~km} / \mathrm{h})$ and rural $(>60 \mathrm{~km} / \mathrm{h})$ speed zones. Areas requiring further research were identified and widespread fitment through the vehicle fleet is recommended. 


\section{Highlights (for review)}

As requested, the Highlights from this research include the following:

- Highlights-Low Speed AEB technology led to a 38\% reduction in real-world rear-end crashes.

- There was no significant difference between urban and rural crash benefits.

- Meta-analysis was an effective method for combining data from various countries.

- Low Speed AEB technology needs widespread fitment for maximum benefits. 


\title{
EFFECTIVENESS OF LOW SPEED AUTONOMOUS EMERGENCY BRAKING IN REAL-WORLD REAR-END CRASHES
}

\author{
Fildes B. Monash University Accident Research Centre, Australia ${ }^{11}$ \\ Keall M. University of Otago, New Zealand \\ Bos N. SWOV, Institute for Road Safety Research, The Netherlands \\ Lie A. Swedish Transport Administration (Trafikverket), Sweden \\ Page Y. European Automobile Manufacturer's Association, Renault, France \\ Pastor C. Federal Highway Research Institute (BASt), Germany \\ Pennisi L. Automobile Club d'Italia (ACI), Italy \\ Rizzi M. Folksam Insurance, Sweden \\ Thomas P. Loughborough University, UK \\ Tingvall C. Swedish Transport Administration (Trafikverket), Sweden
}

\begin{abstract}
This study set out to evaluate the effectiveness of low speed autonomous emergency braking (AEB) technology in current model passenger vehicles, based on real-world crash experience. The Validating Vehicle Safety through Meta-Analysis (VVSMA) group comprising a collaboration of government, industry consumer organisations and researchers, pooled data from a number of countries using a standard analysis format and the established MUND approach. Induced exposure methods were adopted to control for any extraneous effects. The findings showed a 38 percent overall reduction in rear-end crashes for vehicles fitted with AEB compared to a comparison sample of similar vehicles. There was no statistical evidence of any difference in effect between urban $(\leq 60 \mathrm{~km} / \mathrm{h})$ and rural $(>60 \mathrm{~km} / \mathrm{h})$ speed zones. Areas requiring further research were identified and widespread fitment through the vehicle fleet is recommended.
\end{abstract}

\section{Highlights}

* Low Speed AEB technology led to a $38 \%$ reduction in real-world rear-end crashes

* There was no significant difference between urban and rural crash benefits

* Meta-analysis was an effective method for combining data from various countries

* Low Speed AEB technology needs widespread fitment for maximum benefits

\section{Keywords}

AEB Technology, Effectiveness, Meta-Analysis, Real-World, Rear-End Crashes

\section{Acknowledgements}

The authors acknowledge the support of Michiel van Ratingen of Euro NCAP and the Australian NCAP in Organising and supporting this research program, and the Department of Infrastructure and Regional Development in Australia for funding the Australian contribution. In addition, members of the VVSMA committee beyond the authors deserve special credit for their contribution, namely Murray Doyle, Thatcham, UK; Sebastian Döring, VW, Germany; Anders Kullgren, Folksam, Sweden; Stefan Rauscher, BMW, Germany; and Johan Strandroth, Trafikverket, Sweden; as well as all the contributing organisations for self-funding their own research effort.

\footnotetext{
${ }^{1}$ Contact Author - Professor Brian Fildes, Building 70, Monash University, Wellington Rd., Clayton, Victoria, 3800, Australia, Work+61399054369, Mobile+61419375909, email brian.fildes@monash.edu
} 


\section{INTRODUCTION}

Advanced crash avoidance technologies are increasing rapidly in passenger and commercial vehicles as industry, government and the community focus on improved vehicle safety systems. One of the more promising safety technologies that is starting to appear as standard equipment on modern passenger cars and Sport Utility Vehicles (SUV) is Autonomous Emergency Braking (AEB). Autonomous emergency braking systems apply the vehicle brakes when a collision is eminent in spite of any reaction by the driver. In some technologies, the system forewarns the driver with an acoustic signal when a collision is still avoidable, but subsequently applies the brakes automatically if the driver fails to respond.

There are at least two versions of these systems, namely low-speed or "City" systems or high-speed "Inter-Urban" systems that operate at different speed thresholds. These systems commonly consist of an automatic brake function and a forward collision warning sensor and vehicles may offer either single of both functionalities (Euro NCAP, 2014). The AEB "City Safety" system was first introduced by Volvo cars in their XC60 Sport Utility Vehicle around 2009 (ITS International 2013) and more recently, extended the technology as standard equipment in all its passenger vehicles. In recent years, other manufacturers, primarily in European and Japanese models, also offer versions of similar systems in their modern vehicles. The technology operates for vehicle speeds up to $30 \mathrm{~km} / \mathrm{h}$ or $50 \mathrm{~km} / \mathrm{h}$ in some vehicle models.

It is claimed that Autonomous Emergency Braking systems offer substantial reductions in crash avoidance or injury mitigation as shown in Table 1 below. It should be noted with some caution that many of these studies used a range of different technology functionalities and assessment methods.

Table 1: Published studies of benefits of AEB technology

\begin{tabular}{|c|c|c|c|c|c|c|c|}
\hline \multirow{2}{*}{ AEB Report } & \multirow{2}{*}{ AEB Type } & \multirow{2}{*}{$\begin{array}{c}\text { Assessment } \\
\text { Method }\end{array}$} & \multirow{2}{*}{$\begin{array}{c}\text { Crash } \\
\text { Reductions }\end{array}$} & \multicolumn{4}{|c|}{ Injury Reductions } \\
\hline & & & & Fatalities & Serious & Slight & Injuries \\
\hline Sugimoto \& Sauer (2005) & CMBS & $\begin{array}{l}\text { Simulation } \\
\text { rear-end crashes }\end{array}$ & $38 \%$ & $44 \%$ & & & \\
\hline Page et al (2005) & EBA & $\begin{array}{l}\text { Case analysis } \\
\text { Forward crashes }\end{array}$ & & $7.5 \%$ & & & $11 \%$ \\
\hline Najm et al (2006) & ACAS & FOT responses & $6-15 \%$ & & & & \\
\hline Breuer et al (2007) & BAS+ & $\begin{array}{c}\text { Simulation } \\
\text { ped/rear crashes }\end{array}$ & $44 \%$ & & & & \\
\hline Kuehn et al (2009) & CMBS & $\begin{array}{l}\text { Case analysis } \\
\text { front/rear crash }\end{array}$ & $40.8 \%$ & n.a. & n.a. & n.a. & n.a. \\
\hline GDV (2011) & EBA2 & $\begin{array}{l}\text { Case analysis } \\
\text { rear-end crashes }\end{array}$ & $13.9 \%$ & $2.2 \%$ & $9.4 \%$ & $35.7 \%$ & \\
\hline Grover et al (2008) & AEB & $\begin{array}{c}\text { Case analysis } \\
\text { sensitive crashes }\end{array}$ & $30 \%$ & & & & \\
\hline Kusano \& Gabler (2012) & AEB & $\begin{array}{l}\text { Case analysis } \\
\text { rear-end crashes }\end{array}$ & $7.7 \%$ & \multicolumn{2}{|c|}{$50 \%$} & & \\
\hline HLDI (2011) & AEB & Insurance claims & $22-27 \%$ & & & & $51 \%$ \\
\hline Doecke et al (2013) & AEB & $\begin{array}{l}\text { Case analysis } \\
\text { rear-end crash }\end{array}$ & $25-28 \%$ & & & & \\
\hline Chauvel et al (2013) & AEB & $\begin{array}{l}\text { Case analysis } \\
\text { pedestrians }\end{array}$ & $4.3 \%$ & $15 \%$ & $37 \%$ & n.a. & n.a. \\
\hline
\end{tabular}


While many of these evaluations claim substantial benefits, most are based on desk-top evaluations of expected crash and injury outcomes. Unfortunately, there is only limited evidence of their real-world effectiveness in reducing crashes or injuries. Single country crash databases, traditionally used for conducting real-world evaluations, are limited by the slow take-up rates of these new technologies, limited crash data, and lower crash rates by owners of new safer vehicles. New systems are also commonly available on only a few car models and sometimes optional which increases the time needed to assess their real-world effectiveness. One way of potentially speeding up the evaluation process is to adopt a wider approach to collecting and analyzing crash data, rather than simply relying on one country's analysis from their limited crash numbers.

\section{Meta-Analysis}

Classic meta-analysis, commonly used by the medical fraternity, typically combines the findings of various existing published randomized control trials of a common theme to produce a much larger pool of research data, leading to a more robust assessment (Cochran Collaboration, 2013). This approach typically relies on retrospectively published studies that meet established criteria, and while they are very useful for helping establish general trends and outcomes, they are commonly assembled from evaluations (clinical trials) already published in the scientific literature and thus still subject to long delays.

An alternative prospective approach involves a planned collaboration of independent aggregate analyses from data analysts using a common study design. This brings together a much larger pool of data than any one country, has available, speeds-up the process of evaluating safety technologies, and provides a more internationally relevant assessment of the safety benefits than any one single country can provide. In a recent published study (MUNDS) it was shown that it is possible to increase the available relevant crash data by combining data from a number of countries using meta-analyses and thus obtain robust statistical evaluations more quickly (Fildes, et al, 2013).

Meta-analysis has the additional advantage of circumventing the need to work with unit-level data. In ideal circumstances, regression models could be fitted to unit-level data, allowing for more efficient estimation and control for potential confounders. In practice, road safety agencies and police are reluctant to hand over their data at this level to external parties, but are willing to summarise their data at an aggregated level suitable for a metaanalysis.

With Euro NCAP's initiation, a technical group of researchers from government, industry and research organizations was assembled (the Validating Vehicle Safety through Meta-Analysis or VVSMA group) to evaluate the effectiveness of Low Speed Autonomous Emergency Braking technology (AEB city), using this new approach. The objective was to measure the likely reductions in important rear-end injury crashes for vehicles fitted with this safety technology. Case and control vehicles were agreed upon by the whole group and these are listed in Attachment $A$.

\section{Low Speed AEB Technology}

CarAdvice (2014) noted that Low Speed AEB or City Safe technologies are marketed under a variety of names, including City Brake Control (Fiat), Active City Stop (Ford), City Emergency Brake (Volkswagen) and City Safety (Volvo). As their names suggest, this type of AEB technology is geared towards low speed situations, generally under $30 \mathrm{~km} / \mathrm{h}$. These systems rely on radar sensors detecting an emergency situation and apply the brakes as needed. They tend to work most effectively over short distances.

Low speed AEB technology, such as the City Safety system fitted to new Volvo vehicles, operates at speeds between 30 to $50 \mathrm{~km} / \mathrm{h}$. As the name implies, the system is designed to only offer protection in rear-end crashes in mainly urban areas. Low-speed AEB systems use sensors to monitor the road ahead, typically $6-8 \mathrm{~m}$. One common technology is a LIDAR (Light Detection and Ranging) sensor, typically mounted at the top of the windscreen, which determines whether or not there is an object in front of the car which presents a risk. If there is, the AEB system will, 
typically, pre-charge the brakes so that the car will provide its most efficient braking response, should the driver react. If the driver does not respond, the car will automatically apply the brakes to avoid, or in some cases to mitigate, the accident. If, at any point, the driver intervenes to avoid the accident, by hard braking or avoidance steering, the system will disengage (Euro NCAP, 2014).

\section{Induced Exposure}

An induced exposure approach was used in the present paper, as the true exposure with Low-speed AEB may be difficult to obtain in different countries, and could be also associated with some confounding factors. An analysis using induced exposure can be used when the true exposure is not available or not suitable, as argued in Evans (1998), Hautzinger (2003) and Lie et al (2006).

Induced exposure approaches to estimating risk attempt to quantify on-road exposure using counts of crash involvements. The crash types used for these risk estimates generally focus on events where the driver of a given vehicle could be considered to be passively involved in the crash. Such crash events, therefore, are conceptualised as a sampling mechanism and the counts of the crashes are assumed to be proportional to the amount of driving undertaken by a given driver group or vehicle type. Validation of these assumptions has rarely been undertaken. Indeed, at-fault classification is unavailable in some of the countries that provided data here.

A study using New Zealand data compared exposure in terms of distance driven with counts of crash involvements to identify which crash configurations might be preferred as an induced exposure measure (Keall and Newstead, 2009). Two sets of crash types - collisions where the vehicle in question was impacted from the rear and collisions where the driver was adjudged not to be at fault - were found to perform equally well. But even these two best-performing crash types when used to estimate risk showed systematic biases according to the driver characteristics age and sex, and the size of the vehicle (ibid). Despite these limitations, induced exposure methods are widely used in road safety research as they are often the only form of exposure measure available.

Using this approach the crash risk is not calculated by comparing crash involvement to vehicle mileage or the number of registered vehicles with and without the system being evaluated. Crash involvement instead, is compared to a situation assumed or known to be not affected by the safety system (i.e. non-sensitive). In other words, the ratio between the number of crashes sensitive and non-sensitive to low-speed AEB is analyzed across two different crash populations where the only noteworthy difference should be the fitment of low-speed AEB.

\section{METHOD}

The underlying philosophy adopted here involved combining data from a number of countries to overcome the shortage of data and provide earlier results. Unfortunately, database owners are typically unable to contribute actual case records for reasons of confidentiality and legal restrictions. Thus, each database participant agreed to undertake their own analysis using a common format and provide an aggregate analysis for combining overall using a meta-analysis approach. Potential cases and controls are listed in Attachment A.

Crombie and Davies (2009) describe meta-analysis as a statistical technique for combining the findings from independent studies. They note that in medical research, it is commonly used to assess the effectiveness of healthcare interventions by combining data from two or more randomised control trials. While many of these independent studies must meet particular entrance criteria to be included, they are nevertheless independent in that researchers do not necessarily set out with a common data format and thus, some variation naturally exists when combining multiple studies. As noted above, the approach here sets out with each study adopting a common format in their approach ensuring a closer match between studies. It has been validated in previous research (Fildes et al, 2013). 


\section{Agreed Data Format}

The agreed data format was one that all data providers could achieve. Sensitive crash types for the technology focussed on rear-end crashes where the AEB vehicle made impact with another vehicle (striking) or was impacted from behind (struck) in only 2-Car crashes. Those vehicles fitted with AEB were compared with Non-AEB crashed vehicles in sensitive crash types. AEB fitted vehicles were identified from local vehicle knowledge where the technology was known to be standard equipment. The comparison Non-AEB vehicles were similar vehicle types but without the technology. Induced exposure was the method used to control for extraneous influences. All data providers agreed to conduct individual local analysis around a core set of parameters, using their national (policereported) crash database for rear-end crashes from 2009. Induced exposure methods were adopted in each dataset, as explained above. The formula used by each data supplier in the computation was in the form of the estimator of the preventive fraction:

$$
E=1-(a / b) /(c / d)
$$

where:

$$
\begin{aligned}
& a=A E B \text { fitted vehicles as striking vehicle } \\
& b=A E B \text { fitted vehicles as struck vehicle } \\
& c=\text { Non-AEB vehicles as striking vehicle } \\
& d=\text { Non-AEB vehicles as struck vehicle }
\end{aligned}
$$

Definition of striking and struck vehicles was determined using a range of different methods, appropriate from each of the individual database codes. Crash variables include 2-vehicle (car-car) injury crashes that occurred in years 2009 or more recent, using relevant vehicles. Urban (speed limit, $\leq 60 \mathrm{~km} / \mathrm{h}$ ) and rural crashes (speed limit, $>60 \mathrm{~km} / \mathrm{h}$ ) was analysed separately. Non-AEB vehicles were selected from an agreed list of equivalent vehicles.

\section{Meta-Analysis Approach}

The individual analyses were then brought together using meta-analysis. If the population of crashes analysed consists of sensitive crash types combined with comparison crash types, an odds ratio $(a / b) /(c / d)$ will estimate the relative rate of sensitive crashes for the AEB vehicles compared to the same rate for the control vehicles (Fildes et al, 2013).

$$
w=\frac{1}{s e^{2}}
$$

An estimate of the effectiveness of AEB for the set of sensitive crashes was formed by subtracting this odds-ratio from 1, as shown in equation (1) above. Hedges et al. (1998) showed that the optimal weights for meta-analysis are:

where "se" is the standard error of the estimate from a given study.

The odds-ratio has a skewed distribution and has a complex standard error formula. Therefore it is preferable to conduct all calculations on the natural log of the odds-ratios (Wilson, 2000). Finally results are converted back into odds-ratios by the inverse natural log function. The standard error of a logged odds-ratio can be approximated by:

$$
\text { se }=\sqrt{\frac{1}{a}+\frac{1}{b}+\frac{1}{c}+\frac{1}{d}}
$$


Using these weights, the combined effect size, (ES) which is a weighted average of the individual study effect sizes are estimated by:

$$
\overline{E S}=\frac{\sum(w \times E S)}{\sum w}
$$

The standard error (SE) that can then be estimated from:

$$
S E_{\overline{E S}}=\sqrt{\frac{1}{\sum w}}
$$

The overall estimate of effectiveness $(\bar{E})$ is:

$$
\bar{E}=1-\exp (\overline{E S})
$$

\section{Tests of adequacy of estimation method}

The homogeneity analysis tests whether the assumption that all of the effect sizes are estimating the same population mean is a reasonable assumption. The Homogeneity Statistic, $Q$, was calculated as:

$$
Q=\sum\left(w \times E S^{2}\right)-\frac{\left[\sum(w \times E S)\right]^{2}}{\sum w}
$$

This statistic takes the Chi-square distribution with degrees of freedom = number of ESs less than 1 . A statistically significant $Q$ statistic would suggest that the effect sizes are sufficiently different to require more sophisticated estimation methods, such as a random effects model (Wilson, 2000).

Logistic regression was used in assessing the speed zone effects to control for extraneous influences across the various databases. The outcome variable was crash type, set to 1 when the vehicle was striking and 0 for struck (as described above) with explanatory variables AEB (an indicator as to whether the vehicle was AEB equipped or not), country, speed limit (rural or urban) and an interaction between AEB and speed limit. This coefficient of this final term was used to assess whether there was differential effectiveness in different speed limit areas.

\section{RESULTS}

The subsequent results obtained from combining the individual country analyses, using the meta-analysis approach outlined above are listed below. For various reasons, it was not possible to identify these particular countries in the results that followed. Table 2 shows the number of AEB crashed vehicles and non-AEB vehicles used in the VVSMA AEB meta-analysis. While the number of cases varied across these 6 individual countries, they were controlled for a number of similar characteristics (national police data, 2009 crashes and more recent, similar makes and models, etc). 
Table 2: Number of crashes by country, crash type, AEB and Non-AEB vehicles, all speed limits

\begin{tabular}{|llll|}
\hline Country* & \multicolumn{1}{c}{ Crash type } & AEB & Non-AEB \\
\hline \multirow{2}{*}{ Country 1 } & Front to rear & 21 & 202 \\
& Impacted from rear & 84 & 435 \\
\hline \multirow{2}{*}{ Country 2 } & Front to rear & 1 & 138 \\
& Impacted from rear & 4 & 246 \\
\hline \multirow{2}{*}{ Country 3 } & Front to rear & 14 & 434 \\
& Impacted from rear & 16 & 374 \\
\hline \multirow{2}{*}{ Country 4 } & Front to rear & 35 & 404 \\
& Impacted from rear & 59 & 450 \\
\hline \multirow{2}{*}{ Country 5 } & Front to rear & 15 & 105 \\
& Impacted from rear & 24 & 95 \\
\hline \multirow{2}{*}{ Country 6 } & Front to rear & 2 & 85 \\
& Impacted from rear & 1 & 82 \\
\hline
\end{tabular}

* Individual countries, predominantly European, could not be singled out for confidentiality reasons

The resultant country-specific AEB effectiveness estimates, along with the pooled weighted average estimate, is provided in Tables 3 and 4 . The overall estimate of $38 \%$ effectiveness was highly statistically significant $(P=0.0006)$ and represents a $38 \%$ reduction in the sensitive crashes relative to the comparison crash type. A negative percentage (as shown as the lower bound of most country-specific effectiveness estimates) represents an increase in sensitive crashes relative to the comparison crashes. The only country whose estimates was statistically significant taken in isolation was Country 1, although Country 4 was too when the controls were non-AEB Volvos or general controls. The Homogeneity Statistic, $Q$, was calculated to be 1.65 , with no homogeneity issues $(P=0.90)$ (Keall and Newstead, 2009).

Table 3: Country-specific point estimates and $95 \%$ confidence intervals

\begin{tabular}{|l|c|l|r|l|}
\hline Table 3: Country-specific and overall effectiveness estimates with 95\% confidence intervals \\
\hline Country & $\begin{array}{c}\text { Odds } \\
\text { ratio }\end{array}$ & $\mathbf{( 9 5 \% \text { Confidence Limits) }}$ & Point Effectiveness & (95\% Confidence Limits) \\
\hline Country 1 & 0.54 & $(0.32,0.89)$ & $46 \%$ & $(11 \%, 68 \%)$ \\
\hline Country 2 & 0.45 & $(0.05,4.03)$ & $55 \%$ & $(-303 \%, 95 \%)$ \\
\hline Country 3 & 0.75 & $(0.36,1.57)$ & $25 \%$ & $(-57 \%, 64 \%)$ \\
\hline Country 4 & 0.66 & $(0.43,1.03)$ & $34 \%$ & $(-3 \%, 57 \%)$ \\
\hline Country 5 & 0.57 & $(0.28,1.14)$ & $43 \%$ & $(-14 \%, 72 \%)$ \\
\hline Country 6 & 1.93 & $(0.17,21.69)$ & NA* $^{*}$ & NA* \\
\hline Overall & 0.62 & $(0.47,0.82)$ & $38 \%$ & $(18 \%, 53 \%)$ \\
\hline
\end{tabular}

*the preventive fraction is not defined when an increase in prevalence is estimated

Interestingly, there were global differences observed in the ratios between front and rear collisions across the 6 countries listed in Table 2. They varied from around 1:2 for countries 1 and 2 to approximately 1:1 for the others. This was unexpected a-priori, it would be expected to be equal for all countries. The reasons for this variation are not readily apparent but likely to involve differences in entrance criteria for the various databases, occupants' age and sexes, crash distribution types, and possibly different vehicle type (cars and SUVs for instance). While this could be 
worthy following up in future, importantly, it was unlikely to have had any influence on the effectiveness calculations for the low speed AEB technology as both the AEB-equipped and comparison vehicles were assessed on the same basis in the analysis.

\section{Urban and Rural Crashes}

Each country also provided counts of crash involvements according to the speed limit of the crash location: urban $(\leq 60 \mathrm{~km} / \mathrm{h})$ and rural crashes $(>60 \mathrm{~km} / \mathrm{h})$; or other means of defining crash zone. This enabled the analysis to control for the speed limit and adjust for any potential confounding by the location of the crash. It also allowed a test to be conducted as to whether AEB might be more effective in lower speed limit areas than high speed limit areas, given the functionality of the system, although sample size limitations were likely to provide low power for such a test.

Using logistic regression, it was possible to test whether there was any difference in the effectiveness of AEB between urban and rural areas. These findings showed no evidence whatsoever of any differential effectiveness according to speed limit area.

\section{DISCUSSION}

This analysis of crash data from these six countries has shown a clear change in the distribution of crash types for vehicles with AEB relative to control vehicles without this technology. The main meta-analysis found a significant $38 \%$ reduction in crashes where the $A E B$ vehicle impacted the rear of another vehicle, relative to the rate that these vehicles were impacted from the rear by other vehicles. Such a reduction can occur via a reduction in the rate of impacts to the rear of other vehicles by the AEB vehicles, but it can also occur (or be contributed to) by an increase in the rate that $A E B$ vehicles are impacted from the rear by other vehicles, which could be an unintended consequence of more effective braking. As noted above, this requires further analysis.

In a forerunner to the current study (Fildes et al, 2013) in which various countries' data were combined to estimate the effectiveness of Electronic Stability Control (ESC), the countries provided counts of crashes disaggregated by driver age group, vehicle size, year of manufacture, speed zone and road condition (dry/wet/snow/ice). There was a good rationale for such disaggregation: ESC has been shown to have different levels of effectiveness under different road conditions and for different vehicle types (ibid). In that analysis, these various disaggregating variables were then able to be used as explanatory variables in the regression analysis, controlling for potential confounding arising from these factors. Little is currently known about ways that low speed AEB may vary in its effectiveness, unlike ESC. Nevertheless, the current measure of effectiveness may have been influenced by some of the factors listed above that were not available to be used in the analysis. Although not reported in the aforementioned paper, an analysis was conducted to look at the impact on the overall estimated effectiveness of ESC of excluding the control of these potential confounders from the analysis. A 30\% higher estimate was found, indicating the importance - in the case of ESC evaluations - of controlling for such factors, particularly road condition and vehicle size. It is a limitation of the current study that the impact of not controlling for similar factors is unknown.

The figures from previous simulation or case studies listed in Table 1 for rear-end crashes were highly variable and dependent on the method used to compute them. Those using simulation techniques were closest to the real-world benefits reported here (between $38 \%$ and $44 \%$ ). Other methods from case-by-case estimations or insurance claims were much less (between 14\% and 30\%). While injury benefits were not computed in this real-world study, the earlier studies confirm that there is potential for marked reductions in fatal and serious injury reductions from this technology. This needs further research using the VVSMA real-world approach.

The findings from the logistic analysis showed that there were no differences in effectiveness between crashes that occurred overall to those that occurred in urban areas. This might be because most of the crashes observed in this 
analysis predominantly occurred in low speed regions. Thatcham (2009) claimed that these systems are more effective at lower speeds ( $<25 \mathrm{mph}$ ) where more than $75 \%$ of accidents occur, based on insurance findings. The low speed AEB technology is designed to work up to around $50 \mathrm{~km} / \mathrm{h}$ which shows the suitability of this technology in the prevention the bulk of rear-end crashes. Whether the alternative high speed AEB technology is also effective cannot be assumed from these results.

The variation between hitting and being hit with and without low speed AEB technology across the 6 databases was a surprising finding. It may be that the proportional differences were a function of the crash distributions across countries, the ages and sex differences across countries, or personality variation of the drivers. The national data available lacked sufficient detail to address these issues. It could also suggest differences in the data records in the countries that participated where police attendance at a crash can be quite variable. As each country incorporated much the same vehicle mix, it is unlikely that it's a function of major variation in vehicle types. Nevertheless, this is an interesting finding and one that requires further research using more detailed data.

\section{Study Limitations}

As noted above, it was not possible to disaggregate the data by occupants' age, sex and vehicle type as the data provided by the various databases were not aggregated to such a level. This was a function of the need for each data provider to undertake their own analysis based on their inherent limitations. Thus, this is clearly a potential limitation with the analysis reported here. In addition, it would have been useful to have used side-impact crashes as an alternative induced exposure measure as recommended by Keall and Newstead (2009). While this was attempted here, unfortunately, not all of the 6-countries databases had suitable coding for side impact collisions and the results reflected this. This is clearly another topic for further research.

Furthermore, the data provided for the sensitivity analysis did not separate crash types for which AEB might be effective from those where AEB would have little effect. There was some evidence of lower effectiveness when side impacts were used as a comparison crash type but as noted above, these results were not significant. As the means of assessing impacts to the side of the vehicle were not consistent across countries, this finding cannot be considered robust, and is something worthy of further research.

It might be argued that the underlying assumptions of the induced exposure approach should be validated in terms of the not-at-fault assumption to be sure the conclusions are not misleading. In this study, it was not possible to test this assumption as at-fault classifications were not available in all of the national databases involved in the metaanalysis. Thus, care needs to be taken in assuming these findings are totally representative.

Importantly, the findings reported here confirm the advantage of the meta-analysis process adopted here when evaluating safety technology. As seen in Table 2, only one of the six countries reported was able to show significant differences between the AEB and Non-AEB vehicles albeit with broad confidence intervals. This is clear evidence of the benefits of the approach for providing timely real-world evidence of technology effectiveness.

\section{CONCLUSIONS}

The findings showed a surprising 38 percent overall reduction in real-world, rear-end crashes for vehicles fitted with low speed AEB compared to a comparison sample of equivalent vehicles. There was no statistical difference between urban $(\leq 60 \mathrm{~km} / \mathrm{h})$ and rural $(>60 \mathrm{~km} / \mathrm{h})$ speed zones. The meta-analysis approach used in this analysis is a unique academic contribution to the evaluation of vehicle safety technologies internationally and proved to be reliable with robust findings. Areas requiring further research were identified for fine-tuning these findings. Clearly, at this level of effectiveness, low speed Autonomous Emergency Braking (AEB) is potentially an important active safety technology and widespread fitment through the vehicle fleet should be encouraged in the interest of improved vehicle safety. 


\section{Acknowledgements}

The authors acknowledge the support of Michiel van Ratingen of Euro NCAP and the Australian NCAP in Organising and supporting this research program, and the Department of Infrastructure and Regional Development in Australia for funding the Australian contribution. In addition, members of the VVSMA committee beyond the authors deserve special credit for their contribution, namely Murray Doyle, Thatcham, UK; Sebastian Döring, VW, Germany; Anders Kullgren, Folksam, Sweden; Stefan Rauscher and Olaf Jung, BMW, Germany; and Johan Strandroth, Trafikverket, Sweden; as well as all the contributing organisations for self-funding their own research effort. We also thank the reviewers of this paper for their useful and helpful comments.

\section{References}

Aversa A. (2013). Summary of research to evaluate the benefits of a mass dissemination of E-safety technologies AEB, LDW, ISA, ACI Press Conference, Automobile Club of Italy, October $16^{\text {th }} 2013$.

Breuer JJ., Faulhaber A., Frank P. And Gleissner S. (2007). Real world safety benefits of brake assistance systems, Proceedings of the $20^{\text {th }}$ International Technical Conference on the Enhanced Safety of Vehicles (ESV) in Lyon, France, June 18-21, 2007.

CarAdvice (2014). Autonomous emergency braking explained, (downloaded December 2014). http://www.caradvice.com.au/293366/autonomous-emergency-braking-explained/

Clepa (2013). European Automotive Technologies: Smart Solutions for Road Safety, European Association of Automotive Suppliers, CLEPA Safety Event, Brussels, 6 May 2013

Chauvel C., Page Y., Fildes BN. and Lahausse J. (2013). Automatic emergency braking for pedestrians effective target population and expected safety benefits, Paper number $13-0008$, The $23^{\text {rd }}$ International Technical Conference on the Enhanced Safety of Vehicles (ESV) Seoul, Republic of Korea, May 27-30, 2013.

Crombie IK., and Davies HT. (2009). What is Meta-Analysis? Published by Hayward Medical Communications, a division of Hayward Group Ltd., Covent Garden, London, Euro NCAP (2014). Autonomous Emergency Braking http://www.euroncap.com/testsexplained/aeb.aspx

Döcke S.D., Anderson R.W.G., Mackenzie J.R.R., Ponte G. (2012). The potential of autonomous emergency braking systems to mitigate passenger vehicle crashes, Paper presented at the Australasian Road Safety Research, Policing and Education Conference, 4 - 6 October, 2012, Wellington, New Zealand.

Evans L. 1998. "Antilock Brake Systems and Risk of Different Types of Crashes in Traffic". In proceedings of the 1998 ESV Conference. Paper Number. 98-S2-0-12.

Fildes B, Keall MD, Thomas P, Parkkari K, Pennisi L, Tingvall C (2013) Evaluation of the Benefits of Vehicle Safety Technology: The MUNDS Study, Accident Analysis \& Prevention 55:pp. 274-281.

Grover C., Knight I., Okoro F., Simmons I., Couper G., Massie P. and Smith B. (2008). Automated Emergency Brake Systems: Technical Requirements, Costs and Benefits, PPR227, TRL Limited, DG Enterprise, European Commission, April 2008.

Hautzinger H. (2003). Measuring the effect of primary safety devices on accident involvement risks of passenger cars - some methodological considerations, SARAC Project, European Commission, Subtask Report 12-09-2003.

Hedges LV, Vevea JL (1998) Fixed-and random-effects models in meta-analysis, Psychological methods Vol. 3: pp. 486. 
HLDI 2011. Volvo's City Safety prevents low-speed crashes and cuts insurance costs, Status Report, Vol. 46, No. 6 I July 19, 2011

Hummel T., Kühn M., Bende J. and Lang A. (2011). Advanced Driver Assistance Systems, Research Report FS 03, Unfallforschung der Versicherer (GDV), ISBN-Nr: 978-3-939163-37-4, German Insurance Association Insurers Accident Research, Berlin.

ITS International (2013). City Safety reduces low speed accidents on Volvo's XC60 and S60, First published in ITS International, May June 2013 http://www.itsinternational.com/sections/nafta/features/city-safety-reduces-lowspeed-accidents-on-volvos-xc60-and-s60/

Lie A., Tingvall C., Krafft M., Kullgren A. 2006. "The Effectiveness of Electronic Stability Control (ESC) in Reducing Real Life Crashes and Injuries." Traffic Injury Prevention Vol. 7, pages 38-43.

Kuehn M., Hummel T. and Bende J. Benefit estimation of advanced driver assistance systems for cars derived from real-world accidents, Paper Number 09-0317, The $21^{\text {st }}$ International Technical Conference on the Enhanced Safety of Vehicles Conference (ESV) - International Congress Centre, Stuttgart, Germany, June 15-18, 2009.

Keall M. and Newstead S. (2009). Selection of Comparison Crash Types for Quasi-Induced Exposure Risk Estimation, Traffic Injury Prevention, Vol. 10 (1), pp23-29.

Kusano, K.D. and Gabler HC. (2012). Safety Benefits of Forward Collision Warning, Brake Assist, and Autonomous Braking Systems in Rear-End Collisions, Intelligent Transportation Systems, IEEE Transactions, Volume: 13 (4)

Najm, W.G., Stearns, M.D., Howarth, H., Koopmann, J., Hitz, J. (2006). Evaluation of an Automotive Rear- End Collision Avoidance System (technical report, DOT HS 810 569). Cambridge, MA: John A. Volpe National Transportation System Center, U.S. Department of Transportation.

Page Y., Foret-Bruno J. \& Cuny S. (2005). Are expected and observed effectiveness of emergency brake assist in preventing road injury accidents consistent? $19^{\text {th }}$ ESV Conference, Washington DC., USA

Sugimoto Y. and Sauer C. (2005). Effectiveness Estimation Method for Advanced Driver Assistance System and its application to Collision Mitigation Brake Systems. Paper Number 05-0148, the $19^{\text {th }}$ International Technical Conference on the Enhanced Safety of Vehicles (ESV) - Washington D.C. June 6-9, 2005.

Thatcham (2009). Autonomous Emergency Braking, http://www.thatcham.org/aeb

Wilson DB (2000) Meta-analyses in alcohol and other drug abuse treatment research, Addiction 95:pp. 419-438. 


\section{Attachment A: Selected Case and Control Vehicles}

\begin{tabular}{|c|c|c|c|}
\hline Case Vehicles & \multicolumn{3}{|c|}{ Selected Controls } \\
\hline Volvo case models & Volvo Controls & Car by car controls & Sports Utility Vehicles \\
\hline Volvo S60 from w 2010 & Volvo S60 2006 to 2009 & Alfra Romeo 159 from 2006 & Audi Q5 \\
\hline Volvo V60 from w48 2010 & Volvo V70 from w20 2007 & Audi A4 and A6 from 2005 & BMW X3 \\
\hline Volvo XC60 from w20 2008 & Volvo XC70 from w20 2007 & BMW 3 series ( $4 / 5$ door) & Citroen C-Crossover \\
\hline Volvo V70 from w20 2011 & Volvo S80 from w20 2006 & BMW 5 series & Ford Kuga \\
\hline Volvo XC70 from w20 2011 & Volvo XC90 from 2006 & Citroen C5 & Honda CRV from 2006 \\
\hline Volvo S80 from w20 2011 & & Ford Mondeo from 2006 & Hyundai Santa Fe from 2006 \\
\hline \multirow[t]{2}{*}{ Volvo V40 from w20 2012} & & Honda Accord from 2006 & Mercedes GLK \\
\hline & & Mazda 6 from 2006 to 2012 & Mitsubishi Outlander from 2006 \\
\hline Other case vehicles & & Mercedes C Class $4 / 5$ door & Nissan X-Trail from 2006 \\
\hline VW Up - country dependent & & Mercedes E Class $4 / 5$ door & Opel Antra \\
\hline VW CC Çcountry dependent & & Opel Insignia & Peugeot 4007 \\
\hline Mazda CX5 2011-some country & & Peugeot 407 from 2006 & Renault Koleos \\
\hline \multirow[t]{5}{*}{ Mazda 62013 - some countries } & & Peugeot 508 & Toyota RAV4 from 2006 \\
\hline & & Renault Laguna & VW Tiguan \\
\hline & & Skoda Suberb & \\
\hline & & Toyota Avensis & \\
\hline & & VW Passat & \\
\hline
\end{tabular}

\section{NOTES:}

1. Speed threshold increased from $30 \mathrm{~km} / \mathrm{h}$ to $50 \mathrm{~km} / \mathrm{h}$ in Volvo models w 20 from 2012

2. Not all models were available or sold apart from Volvo XC60 in every country

3. Not all models listed (apart from Volvo) were sold with Low Speed AEB in all countries

4. Volvo XC60 was the predominant case model across all countries 